\title{
Ausência de projetos civilizacionais nos primeiros estudos sociais brasileiros"
}

\author{
Maria José de Rezende ${ }^{l}$ \\ Universidade Estadual de Londrina
}

\begin{abstract}
A finalidade deste estudo é demonstrar que alguns dos primeiros pensadores sociais brasileiros (Sílvio Romero, Euclides da Cunha e Manoel Bomfim) já se encontravam fortemente envolvidos na discussão sobre as (im)possibilidades de o país construir um projeto civilizacional capaz de transfigurar a sociedade e o Estado brasileiro. Constata-se que eles eram influenciados pelos principais problemas das discussões sociológicas positivistas e evolucionistas que tomavam o processo civilizacional como algo dotado de linearidade e de diretividade. Todavia, suas posições eram desconfortáveis, uma vez que eles tinham a sensação de estarem sendo tragados por uma concepção européia de progresso totalmente incompatível com a realidade social brasileira. Havia uma grande dificuldade, em todos eles, de lidar com os avanços e recuos, idas e vindas, progressos e regressos, evolução e regressão presentes nos processos civilizacionais, o que pode ser explicado pelas suas filiações às perspectivas pautadas na inexorabilidade histórica.
\end{abstract}

Palavras-chaves: Processo e projeto civilizacional - Progresso - Evolução - Nação - Desigualdades
The purpose of this study is to show that some of the first Brazilian social thinkers (Sílvio Romero, Euclides da Cunha and Manoel Bomfim) were already deeply involved in the discussion concerning the (im)possibilities for the country to develop a civilizational project capable of transforming the society and the Brazilian state. It is observed that they were influenced by the main problems related to the positivist and evolutionist sociological discussions that considered the civilizational process as something endowed with linearity and directivity. However, their positions were not comfortable, once they had the feeling of being swallowed by and European concept of progress completely with the Brazilian social reality. All of them had a great difficulty in dealing with the advances and retreats, improvements and failures, evolution and regression present in the civilizational processes, what can be explained by their affiliation to the perspective based on the historical inexorability.

Keywords: Civilizational process and project - Progress - Evolution - Nation - Inequalities.

\footnotetext{
* Lack of civilizational projects in the first Brazilian social studies

${ }^{1}$ Professora de Sociologia, Universidade Estadual de Londrina. Endereço para correspondências: Rua Pio XII, 335, Apto. 1104, Londrina, PR, 86020-914 (mjderezende@gmail.com).
} 


\title{
HUMANAS
}

\section{Introdução}

\begin{abstract}
A noção de projeto civilizacional está sendo empregada para definir um conjunto de aprendizado individual e coletivo que possibilita uma vivência voltada, crescentemente, para melhorias sociais e políticas potencializadoras de relações cada vez mais democráticas. Em tais condições, os diversos segmentos sociais conseguem construir canais para influenciar as decisões daqueles que estão no poder. A defesa tanto de uma educação republicana capaz de solapar o oligarquismo, quanto de um processo sociopolítico que vencesse os descasos dos dirigentes com os povos mais pobres, a exclusão e as desigualdades econômicas e políticas, está sendo tomada aqui como parte de um projeto civilizador, o qual foi amplamente problematizado, discutido e defendido por alguns pensadores sociais desde o final do século 19. Os problemas que orientam esse artigo são os seguintes: De que modo Sílvio Romero (1851-1914)², Euclides da Cunha (1966-1909) ${ }^{3}$ e Manoel Bomfim (1868-1932) ${ }^{4}$ estiveram, cada um a seu modo, preocupados com a necessidade de o país formular um projeto civilizacional? E o que eles entendiam por este último? Indaga-se, ainda, de que maneira o ambiente intelectual, de suas épocas, moldado pelo positivismo, pelo darwinismo social e pelo evolucionismo sociológico teve um papel significativo na definição deste projeto?
\end{abstract}

(Des) (In) Civilização são temas que percorrem, ao longo de séculos, as reflexões clássicas e contemporâneas das Ciências Sociais. Eles têm sido recorrentes nas principais obras sociológicas. Herbert Spencer (1904; 1904a ; 1904b; 1972), Augusto Comte (1976), Emile Durkheim (1984), Georg Simmel (1986; 1988), Max Weber (1985; 1991), Werner Sombart (1953; 1979), Alfred Weber (1960), entre outros, cada um a sua maneira, estiveram voltados para identificar avanços e não-avanços civilizacionais nas sociedades ocidentais modernas.

\footnotetext{
2 "Nascido em 1851, no interior do Sergipe, de onde saiu em busca de ação política e de consagração literária, Sílvio Romero, com 29 anos veio para o Rio de Janeiro, onde alcançou uma notoriedade feita de louvor e de rancor, vindo a falecer em 1914. Como a maior parte de seus companheiros de ofício, ele, que foi jornalista, crítico, historiador e professor, acreditou que o espírito e o método científicos deviam ser estendidos a todos os domínios da vida intelectual e moral. Como Manoel Bomfim, com quem brigou até a morte e, Euclides da Cunha, de quem foi amigo e admirador, preocupou-se em entender o Brasil, para o que dedicou toda uma vida..." (REZENDE MOTA, 2000, p. 17-18).

${ }^{3}$ Euclides da Cunha nasceu no estado do Rio de Janeiro. Foi escritor, sociólogo, historiador, repórter e engenheiro. "As interpretações de Euclides da Cunha sobre o Brasil floresceram na última década do século XIX e na primeira do século XX. O pano de fundo de suas reflexões foram os acontecimentos sociais e políticos que tiveram início com a independência" (REZENDE, 2002; p. 1).

${ }^{4}$ Manoel Bomfim nasceu, assim como Sílvio Romero, no estado de Sergipe em meados do século 19. Estudou Medicina no Rio de Janeiro e Pedagogia na França. Foi político, historiador e educador. Suas principais reflexões foram desenvolvidas entre 1905 e 1932. Ele "elaborou uma ampla discussão sobre a atuação das principais forças políticas no Brasil a partir da independência. Ele constatava que, apesar de pouco mencionado, havia-se desenvolvido no país, após 1822, um significativo movimento em prol da nacionalidade brasileira..." (REZENDE, 2003; p.77).
} 


\section{Ausência de projetos civilizacionais nos primeiros estudos sociais brasileiros}

Na sociologia contemporânea, Norbert Elias (1994; 2001; 2006; 2006 ; 2006b; 2006c) reelaborou o debate teórico e político acerca dos processos civilizacionais e descivilizacionais em vista de uma perspectiva histórica de longa duração ${ }^{5}$. (1994; 1998; 1999; 2006; 2006 ; 2006 b; 2006c).

Norbert Elias (1897-1990) emprega a noção de processos civilizacionais e descivilizaçionais de modo distinto dos cientistas sociais que supõem que a noção de civilização traz consigo uma carga, ora extremamente negativa porque traz imbutida a defesa de um padrão de organização social que remete sempre à superioridade de alguns povos (os civilizados) e à inferioridade de outros (os selvagens, primitivos, bárbaros, incivilizados) ora inteiramente positiva e salvacionista. A oposição entre civilização e descivilização, em Elias, não é posta de modo linear nem centrada em explicações pautadas na relação entre causa e efeito ${ }^{6}$. Ou seja, ele rechaça assertivas tais como: a industrialização é a causa, e o processo civilizador, o efeito. A seu ver é muito simplista eleger um fenômeno como causa e o outro como efeito. É ingenuidade também conceber o progresso econômico como aquele que desempenhou um papel primordial nos avanços civilizacionais. Essas fórmulas simples de explicação são superadas em seus escritos pela busca da interação de vários processos capazes de formar um entrançado de jogos configuracionais capazes de impulsionar e/ou deter os processos civilizacionais. Os indivíduos e a sociedade promovem simultaneamente processos civilizacionais e descivilizacionais 7 . Muitas vezes, os ciclos civilizacionais operam, ao mesmo tempo, com ciclos que vão justamente em sentido oposto (ELIAS, 2006a). Norbert Elias define da seguinte maneira os processos civilizacionais e descivilizacionais:

Pode-se dizer que entre os principais critérios para um processo de civilização estão as transformações do habitus social dos seres humanos na direção de um modelo de autocontrole mais bem proporcionado, universal e estável. Sem jamais se libertarem completamente das coações exteriores,

\footnotetext{
${ }_{5}^{5}$ Norbert Elias em Tarde demais ou cedo demais (2001) explica as razões de seu desacordo com a classificação de sua obra como sociologia histórica. Ele diz que essa designação nasceu no seio de uma sociologia que se refugia inteiramente no presente e pretende convencer a todos de que a análise dos processos históricos de longa duração acaba por subordinar a sociologia à história. Ele diz que não é disso que trata seu interesse pela história, pois assim como Marx, Max Weber, Alfred Weber, Sombart e Mannheim ele estava interrogando o passado sobre assuntos sociológicos e não históricos.

${ }^{6}$ Ademir Gebara tem uma proposta interessante sobre a aplicação da noção de (des)civilização de Norbert Elias para pensar a América Latina. Ele diz que a colonização civilizadora gerou, continuamente, um processo descivilizador "en la medida en que la violência en la destrucción de las poblaciones autóctonas implicava su eliminación física, en especial en lo que hace a sus liderazgos" (GEBARA, 2009, p.26). Ele assinala que a colonização produziu descivilização porque destruiu valores, identidades e lideranças não somente dos indígenas, como também dos africanos. Ver ainda: (GEBARA, 2005; 2008).

${ }^{7}$ Sobre as possibilidades de buscar inspiração em Norbert Elias para pensar alguns processos sociais na América Latina (ver: KAPLAN, 2008; CARVALHO \& BRANDÃO, 2005; KAPAN y ORCE, 2009).
} 
as autocoações ganham maior autonomia no curso do processo humano de civilização, em contraposição às coações exteriores. A simetria da autorregulação na relação entre todos os seres humanos e em quase todas as situações da vida cresce... Em conexão com a crescente autonomização das instâncias individuais de autorregulação - das quais fazem parte o entendimento e a consciência, o ego e o superego -, amplia-se também manifestamente o alcance da capacidade de um ser humano de se identificar com outros seres humanos, em relativa independência do grupo a que pertençam, e portanto amplia-se também sua capacidade de sentir simpatia por eles. Descivilização ${ }^{8}$ significa então uma transformação em direção oposta, uma redução do alcance da simpatia (ELIAS, 2006; p. 24-5).

Processos civilizacionais são sinônimos, para Norbert Elias, de autorregulação individual e social ${ }^{9}$. Isso permite tentar detectar nas reflexões de alguns intérpretes do Brasil - tais como Sílvio Romero, Euclides da Cunha e Manoel Bomfim $^{10}$ - como os indivíduos e a sociedade davam ou não demonstração de que estavam buscando formas (políticas, econômicas, culturais, sociais) de se orientarem em razão dos interesses púbicos. Se há, como afirma Elias, diferenças entre indivíduos e nações no que diz respeito ao sujeitamento aos interesses coletivos, pode-se perguntar o seguinte: Como os pensadores sociais brasileiros problematizaram essas diferenças?

${ }^{8}$ Pode-se afirmar, então, que o conceito de incivilização diz respeito a inexistência de um projeto coletivo de nação. "São os processos especiais de civilização que - de tribo para tribo, de nação para nação, em suma, de unidade de subsistência para unidade de subsistência - diferem em função das particularidades de seu destino social. Analogamente, é variado o desenvolvimento dos processos especiais de civilização, assim como de cada figuração dos modelos de civilização. Estes últimos encontram uma de suas expressões mais prementes no habitus social comum dos indivíduos que formam entre si uma determinada unidade de subsistência, por exemplo uma tribo ou Estado. Eles são herdeiros não só de uma linguagem específica, mas também de um modelo específico de civilização e, portanto, de formas específicas de auto-regulação, que eles absorvem mediante o aprendizado de uma linguagem comum e nas quais, então, se encontram: no caráter comum do habitus social, da sensibilidade e do comportamento dos membros de uma tribo ou de um Estado nacional" (ELIAS, 2006, p.23).

${ }^{9}$ Assinale-se que não há qualquer similaridade entre a noção de processo descivilizacional de Norbert Elias e a noção de choque de civilização de Samuel Huntington (1997), o qual faz a seguinte afirmação: "A política mundial está sendo reconfigurada seguindo linhas culturais e civilizacionais. Nesse mundo, os conflitos mais abrangentes, importantes e perigosos não se darão entre classes sociais, ricos e pobres, ou entre outros grupos definidos em termos econômicos, mas sim entre povos pertencentes a diferentes entidades culturais" (HUNTINGTON, 1997, p.97).

${ }^{10}$ Num outro artigo foi feita a análise de outros pensadores sociais: Fernando de Azevedo, Sérgio Buarque de Holanda, Celso Furtado e Raymundo Faoro. 


\section{Ausência de projetos civilizacionais nos primeiros estudos sociais brasileiros}

M. J. de Rezende

Norbert Elias insiste que a análise do processo civilizador sugere que a disponibilidade para o autoajustamento aos interesses comuns tem sido menos permanente em algumas sociedades do que em outras e que é preciso investigar a efetividade dos padrões sociais que impulsionam e/ou rechaçam a autossujeição (ELIAS, 2006). A observância de normas, de leis e de regras orientadas por critérios sociais e pelo interesse coletivo indica que há um padrão de regulação (da sociedade) e de autorregulação (individual) em andamento.

Pode-se dizer que muitos escritos de alguns intérpretes do Brasil estiveram voltados para compreender as disposições sociais e individuais para a observância dos interesses coletivos, das normas constitucionais, das regras sociais e políticas que fossem capazes de favorecer a emergência de um projeto de nação mais inclusivo e democrático. Os escritos de Euclides da Cunha e de Manoel Bomfim podem ser tomados como exemplo disso. Euclides da Cunha indagava no texto Da Independência à República ${ }^{11}$ (1966) se as dificuldades de geração de procedimentos civilizadores estavam inscritas nos indivíduos e/ou na sociedade brasileira. Ele respondia que estavam insculpidas nos dois.

Esse artigo não está buscando encaixar as teses de Norbert Elias à realidade social brasileira. Não há essa intenção em hipótese alguma. Pretende-se sim demonstrar que o debate acerca da geração de processos civilizacionais entendidos como aqueles capazes de gerar ou conter uma melhor distribuição do poder, da riqueza e do bem-estar social - estiveram presentes nas principais reflexões propositivas desenvolvidas no país desde o final do século 19.

Quando alguns pensadores sociais - tais como: Euclides da Cunha, Manoel Bomfim, Fernando de Azevedo (1958; 1958 ; 1958b; 1966), Sérgio Buarque de Holanda (1972; 1972a ; 1976; 1987), Celso Furtado (1964; 1978; 1992; 1998) e Raymundo Faoro $(1989 ; 1991 ; 1994)$ - advogavam a necessidade de implantação de processos capazes de distribuir renda, recursos, serviços sociais básicos como educação e saúde para todos os brasileiros, verifica-se que eles estavam tentando detectar até que ponto o país seguia ou não rumo a mudanças civilizatórias. Tornar uma nação mais igualitária e democrática era, então, sinônimo de avanços civilizacionais. O combate ao oligarquismo, ao patrimonialismo, à exclusão social e política também o era. Neste artigo, todavia, serão analisados somente aqueles três primeiros pensadores. Os demais foram discutidos em outro artigo.

As discussões de Sílvio Romero (1851-1914) sobre a tortuosa política brasileira que se instaurava em 1889 com a proclamação da República, sua crítica ao oligarquismo, ao presidencialismo e à ditadura instaurada pelos primeiros governantes após o fim da Monarquia, seu apelo para que os dirigentes envidem esforços a fim de gerar, no país, uma educação republicana,

${ }^{11}$ Este texto foi escrito em 1900 


\section{HUMANAS}

sua crítica às condições de pobreza de uma parte expressiva dos brasileiros que mourejam por aí abatidos, famintos (Romero, 1943; 1969; 1977; 1979) e sem perspectivas de dias melhores, seu espanto diante da morosidade das mudanças sociais e políticas, e diante de outras questões, demonstravam que suas reflexões se ocupavam de esclarecer a vigência de um jogo de forças capazes de eternizar uma lógica descivilizacional, por excelência.

Cabe, então, esclarecer que se está utilizando a noção de descivilização para definir o empenho de diversos segmentos sociais dominantes e dirigentes, ao longo da história do país, para rechaçar toda e qualquer possibilidade de efetivação de canais de participação e de comunicação entre os que estão no poder e os que são atingidos pelos efeitos das ações daqueles que controlam a vida política nacional. São procedimentos descivilizadores todos os investimentos que, intencionalmente ou não, destroem a possibilidade de surgirem formas de balizamentos das ações dos dirigentes e dominantes. São-no também todas as medidas que visam esvaziar os enfrentamentos, os conflitos e o fortalecimento do espaço público e das demandas coletivas. Considera-se, então, que são descivilizadores todos os atos que, desde a formação do Estado nacional, tentaram impedir a expansão de espaços por onde os direitos sociais e políticos pudessem ganhar corpo. São esforços civilizacionais aqueles que visam sedimentar práticas cidadãs e descivilizacionais os que bloqueiam as lutas por reconhecimento de direitos e pela sua efetivação.

Euclides da Cunha (1866-1909) talvez seja o pensador social que mais diretamente lidou com a noção de civilização contraposta à descivilização. Seus escritos, tais como Os sertões ${ }^{22}$ (1995), Contrastes e confrontos (1966a), À margem da história (1966b), Da independência à República (1966), Civilização (1904), Garimpeiros (1966c), Plano de uma cruzada (1966d), Conflitos inevitáveis (1966e), Nativismo provisório (1966f), Temores vãos (1966g), entre outros, lidaram obstinadamente com uma pergunta que acompanhava sempre suas indagações: estaria o país condenado, para sempre, a processos descivilizadores que eram verificáveis através da matança, do chicote, da miséria, do abandono, do analfabetismo e da pobreza que condenavam uma parte expressiva dos brasileiros. Todavia, ele insistia que não havia outro caminho: ou o país voltava-se para esforços civilizatórios ou, mais cedo ou mais tarde, pereceríamos todos.

Também os textos $\left(1931 ; 1931^{\text {a }} ; 1997 ; 1993\right)$ de Manoel Bomfim (18681932) buscavam desvendar os caminhos sociais, políticos e econômicos que o país vinha trilhando desde o processo de colonização. Ele se atinha às singularidades brasileiras definidas em razão tanto de motivos internos quanto de motivos externos. Ocupava-se, assim, por um lado, em questionar um processo civilizacional, que se identificava com os caminhos trilhados pela Europa,

${ }^{12}$ A primeira edição da obra Os sertões foi publicada em 06 de dezembro de 1902. 


\title{
Ausência de projetos civilizacionais nos primeiros estudos sociais brasileiros
}

e, por outro, em aproximar-se das perspectivas que advogavam que a junção do socialismo e da democracia era o caminho para vencer a supremacia dos processos descivilizacionais assentados nas exclusões sociais e políticas.

Há diferenças entre os pensadores mencionados neste artigo quanto ao olhar que eles lançavam sobre a vida social e política brasileira. Sílvio Romero e Euclides da Cunha eram mais pessimistas em relação à superação das condições nas quais o país se encontrava. Manoel Bomfim, no entanto, ora parecia crer que o Brasil encontraria meios para superar as desigualdades ora demonstrava-se absolutamente incrédulo. Veja-se o que dizia ele:

\begin{abstract}
Mesmo os mais ousados entre os homens públicos, os mais revolucionários, são tão conservadores como os conservadores de ofício... São revolucionários até a hora exata de fazer a revolução, enquanto a reforma se limita às palavras; no momento da execução, o sentimento conservador os domina e o proceder do amanhã é a contradição formal às ideias. Começa porque, mesmo revolucionário hoje, a sua aspiração mais viva é ver, no dia seguinte, toda a gente conforme com os seus atos, é ver que todos vêm aderir a eles. E a adesão se faz efetivamente; não há nada que se oponha a isto; amanhã será tudo como ontem (BOMFIM, 1993; p. 164)
\end{abstract}

As noções de civilização e descivilização estão sendo inspiradas ${ }^{13} \mathrm{em}$ Norbert Elias (1994; 1998; 1999; 2006), todavia, elas estão sendo utilizadas para caracterizar os impulsos e os contraimpulsos que foram gerando e/ou negando possibilidades de emergir tanto novas relações de poder capazes de se contrapor a um padrão de domínio já sedimentado quanto novas instituições voltadas para redefinir procedimentos políticos, administrativos, jurídicos e sociais.

\section{Sílvio Romero, Euclides da Cunha, Manoel Bomfim e as dificuldades civilizacionais no Brasil}

Deve-se perguntar o seguinte: Havia nas indagações desses intérpretes do Brasil, acima mencionados, uma preocupação com o que Norbert Elias caracterizava como processo civilizacional? Pode se dizer que as suas reflexões continham, sim, elementos do debate acerca dos avanços e não-avanços civilizacionais.

\footnotetext{
${ }^{13}$ Estão surgindo, na atualidade, discussões sobre a América Latina inspiradas na obra de Norbert Elias (ver KAPLAN, 2008).
} 


\section{HUM AN AS}

Entretanto, eles não pensavam a realidade brasileira de maneira processual, mas sim de modo linear e diretivo. Orientados ora pelo positivismo, ora pelo evolucionismo spenceriano ${ }^{14}$, ora pelo darwinismo social ${ }^{15}$ eles fundaram suas análises em dicotomias, tais como: civilizados e incivilizados, superiores e inferiores ${ }^{16}$, homogêneos e heterogêneos, modernos e atrasados, povos capacitados e povos incapacitados, etc.

Suas reflexões, levando-se em conta as diferenças importantes que há entre elas - pois não se pode dizer que Sílvio Romero e Manoel Bomfim não tentavam explicações diferentes para as dificuldades sociais brasileiras - alimentavam-se numa mesma fonte: a que supunha a existência de uma possível irreversibilidade da história. Todos eles faziam apelos à história nos moldes evolucionistas, o que os levava a examinar a história do país para que pudessem encontrar as regularidades das ações sociais, econômicas e políticas indicadoras de que o Brasil estava trilhando, no final do século 19 e primeiras décadas do século 20, um caminho construtor da condição de nação civiliza$\mathrm{da}^{17}$. Não se deve supor, no entanto, que essa discussão aparecia de maneira serena em seus escritos. Perturbavam seus espíritos a eterna dúvida sobre as possibilidades de o país vencer as mazelas sociais, políticas e econômicas.

Há momentos, em que tais dúvidas apareciam com muita força nos escritos de todos eles. Silvio Romero, não obstante ser defensor de muitas (mas não de todas) ideias evolucionistas de Herbert Spencer (1904; 1904ª ; 1904b; 1904c; 1972), duvidou, em muitos momentos, do modo do evolucionismo apelar à história para atestar uma dada linearidade histórica. Ele desdenhava da obsessão dos seguidores de Spencer pela ideia de repetição. No entanto, essa discussão não era ponto pacífico nem mesmo nos escritos de Spencer, o qual de um lado, sob a influência das ideias lamarckianas:

[...] considerava que dentro das sociedades humanas havia um processo de modificação mútua em movimento contínuo entre as várias instituições de controle social e as características dos indivíduos.

\footnotetext{
${ }^{14}$ Sobre isto, ver: REZENDE (2003).

15 "A diferenciação (fundamento do evolucionismo spenceriano) vê a sociedade como análoga aos organismos simples, crescendo ao longo de sua vida; a seleção natural (fundamento do darwinismo social) vê as sociedades como análogas à variedade de espécies (populações de organismos), algumas das quais selecionadas como adaptações favoráveis, outras não" (COLLINS, 1988; p. 13).

${ }^{16}$ Antônio Cândido (1990) afirma que o evolucionismo sociológico estava impregnado da convicção de que havia raças inferiores e raças superiores.

${ }^{17}$ Herbert Spencer (1820-1903) pressupunha que havia um percurso linear que as diversas sociedades seguiam. Todas iam "do estado simples [sociedades isoladas entre si, tendo todos os seus membros atividades idênticas ou similares e destituídas de organização política] para o complexo [em que aparecem a divisão do trabalho entre os indivíduos e a divisão de funções entre segmentos, adquirindo importância decisiva a organização política hierárquica" (SZTOMPKA, 1988; p. 184).
} 


\title{
Ausência de projetos civilizacionais nos primeiros estudos sociais brasileiros
}

\begin{abstract}
Dessa forma, as sociedades tendiam a se tornar progressivamente mais integradas, mais por consenso do que pela força, ainda mesmo quando a divisão do trabalho (a diferenciação) aumentava. Por outro lado, no entanto, seguindo o princípio da sobrevivência do mais capaz e a extensão darwiniana disso, fazia sobressair a parte desempenhada na evolução das sociedades pelo conflito social, e mais notavelmente pela guerra (GOLDTHORPE, 1971, p.87).
\end{abstract}

Quando os pensadores brasileiros aqui discutidos insistiam na busca de elementos que indicassem que o país rumava para a superação da condição incivilizada, eles estavam dialogando com esses pressupostos de Spencer de que era detectável nas diversas sociedades um movimento contínuo entre as instituições e os indivíduos. Esses dois últimos modificavam-se simultaneamente. Não somente as instituições cambiavam-se, mas também os indivíduos. Isso era, para Spencer, sinônimo de avanços civilizacionais que seguiam de uma forma linear e diretiva rumo a um tipo de sociedade menos militarizada e menos coercitiva, ideia que ele praticamente abandonou em um de seus últimos escritos - chamado Da civilização - que foi publicado na obra Faits et commentaires (1904c), nos primeiros anos do século 20.

Neste artigo, e também em outros que fazem parte desta sua última obra (1904), Spencer parecia duvidar de que haveria um progresso civilizacional linear conforme ele havia suposto anteriormente. Um pensador social brasileiro que se mostrou desconcertado com a mudança de posição de Herbert Spencer foi Euclides da Cunha que demonstrou isso em um artigo intitulado Civilização que foi publicado no Jornal $O$ Estado de S. Paulo em 10 de julho de 1904. Sílvio Romero não pareceu incomodado, já que ele vinha, há alguns anos, contestando a rigidez do evolucionismo spenceriano que supunha uma direcionalidade inquestionável a todos os povos ao afirmar em The study of sociology que "as sementes de civilização existentes nos aborígenes e distribuídas pela terra, viriam certamente, com o correr do tempo, a cair aqui e aí em circunstâncias adequadas a seu desenvolvimento" (SPENCER, 1961; p.309).

Quais elementos tornam possível considerar que os intérpretes do Brasil, analisados aqui, buscavam indicações de que o país seguia um percurso civilizador? Pode-se dizer que eles buscavam saber se o país estava ou não, no final do século 19 e início do 20, numa rota civilizacional, a qual eles entendiam de modo distinto, mas com uma base comum que pode ser resumida da seguinte maneira: a geração de indivíduos e de instituições que estivessem em condições de voltar-se para a formação de um interesse nacional, coletivo, público. 


\title{
HUM ANAS
}

No texto Da Independência à República (1966), Euclides da Cunha, influenciado por Spencer, procurava no cotidiano da vida política brasileira encontrar formas indicadoras de que o autoritarismo reinante no século 19, principalmente nas décadas de 1820 e 1830, era somente um estágio necessário na construção de uma vida política na qual as coações externas pudessem ser paulatinamente diminuídas. Este tipo de raciocínio de Herbert Spencer influenciou Euclides da Cunha que passava a justificar ideologicamente períodos autoritários como o da Regência, na década de 1830.

Norbert Elias, interessado em construir uma análise não-ideológica na sociologia, não via qualquer positividade nos períodos ditatoriais. Ele fazia a seguinte afirmação acerca dos processos civilizacionais:

\begin{abstract}
Em uma investigação de longo alcance, descobrese que o equilíbrio entre coações exteriores e autocoações - e, com isso, também o equilíbrio entre autocoações e coações das pulsões e o tipo de assentamento individual das autocoações no curso do processo da civilização humana - transforma-se no sentido de uma direção específica. Em estágios iniciais de desenvolvimento, portanto (por exemplo) em estágios representados por tribos e outras unidades de subsistência pré-estatais, as instâncias de autocoação são habitualmente mais permeáveis às pulsões, inconstantes, débeis, lábeis e menos autônomas. Elas necessitam de apoio e reforço constantes por meio de coações exteriores (ELIAS, 2006; p. 23).
\end{abstract}

A indagação de base que os pensadores brasileiros faziam votava-se para a tentativa de verificar, ainda que com pesquisas acidentais ${ }^{18}$, se os principais acontecimentos do final do século 19, tais como o fim da escravidão (1888) e a instauração da República (1889) indicavam a possibilidade de que haveria a emergência de novos processos econômicos, políticos, sociais e educacionais capazes de fazer emergir novas mentalidades, novas práticas sociais e políticas, novas instituições, novos agires, novas atitudes.

Como eles supunham a necessidade de emergirem mudanças substantivas que modificassem indivíduos e instituições ao mesmo tempo, pode-se dizer que havia em suas preocupações elementos de busca e de detecção de um ainda incipiente percurso civilizacional. Por isso, é possível, então,

\footnotetext{
${ }^{18}$ Em A sociologia no Brasil, Florestan Fernandes (1977) afirmava que a pesquisa de Euclides da Cunha que deu origem a obra Os sertões, tinha sido uma pesquisa acidental. Assim denominada por não estar norteada por um método de investigação sistemático.
} 


\section{Ausência de projetos civilizacionais nos primeiros estudos sociais brasileiros}

explorar alguns pontos de suas reflexões acerca das noções de civilização e descivilização para demonstrar que suas discussões se inscrevem num amplo debate desenvolvido no interior do pensamento social em geral.

Suas reflexões podem ser confrontadas tanto com o debate clássico quanto com o debate contemporâneo que ganhou proeminência do decorrer do século 20. É possível apontar alguns elementos de suas reflexões visando averiguar o quão distante suas abordagens estavam, por exemplo, de abordagens como a de Norbert Elias. Isto não significa, porém, que se pretende encontrar pontos de conexão, de semelhanças e/ou de dessemelhanças entre o sociólogo alemão que construiu uma reflexão tendo em vista, fundamentalmente, a realidade europeia ${ }^{19} \mathrm{e}$ os interpretes do Brasil ora estudados.

Um dado que se deve destacar é que Norberto Elias em seus diversos escritos publicados em Introdução à Sociologia (1999) traçava um diálogo com os cientistas sociais (Spencer, Comte, Saint-Simon, Durkheim, Weber) que haviam se ocupado, ora mais ora menos, do debate acerca das possibilidades e impossibilidades de avanços civilizacionais. Elias não desconsiderou, em momento algum, o debate anteriormente realizado acerca do desenvolvimento civilizacional. Lançou ele um olhar especial sobre Durkheim (1994) que, por exemplo, no livro A divisão social do trabalho, discutiu as formas de direito (repressivo e/ou restitutivo), as quais definiam as formas de solidariedade mecânica ou orgânica.

Durkheim buscava demonstrar que a passagem do direito repressivo para o direito restitutivo indicava um ponto incontestável no caminho civilizador. Elias ateve-se, também, aos escritos de Herbert Spencer que atestaram, durante toda a segunda metade do século 19, que as sementes civilizacionais haviam caído por toda parte e que, mais dia menos dia, iriam frutificar. O principal pensador do evolucionismo sociológico argumentava que a emergência de uma sociedade industrial não-militarizada, fundada na interiorização de regras de vivência que fossem capazes de dispensar mais e mais a coerção, era indicação de que a humanidade caminhava rumo a uma evolução civilizacional.

Norbert Elias criticou todas as discussões lineares e diretivas que tomavam o processo civilizacional como uma linha reta. Diferentemente de Durkheim, de Spencer, de Comte, ele argumentava que não havia indicações, com base nas pesquisas históricas de longa duração, de que o processo civilizacional era sinônimo de um progresso inconteste. Ele ressaltava que o grande problema de algumas teorias clássicas era a crença cega na linearidade, na evolução e na diretividade histórica. Não dá para supor, no entanto, que Elias considerava possível, nas Ciências Sociais, o simples descarte da noção de evolução social,

${ }_{19}$ Jack Goody em $O$ roubo da história (2008) faz uma crítica contundente à obra de Norbert Elias. Em entrevista sobre este livro, em 2009, ele diz: "Elias me parece atribuir a civilização à Europa e negligenciar o resto" (GOODY, 2009; p. 2). 


\section{HUMANAS}

todavia, ele questionava a perspectiva de inevitabilidade que o evolucionismo continha. Sua crítica destacava que o maior equívoco que as vertentes evolutivas e direcionais perpetuavam era não olhar para as capacidades de mudanças diferentes que as diversas configurações possuíam ${ }^{20}$. Ao necessitar de modelos explicativos genéricos a sociologia evolutiva vai-se fixar na relação entre causa e efeito (Elias, 1999).

Assinale-se que os intérpretes do país, ora analisados, constroem reflexões sobre as dificuldades do processo civilizacional brasileiro, levando em consideração a construção de uma sociedade mais igualitária e mais inclusiva, calcadas inteiramente nessas perspectivas lineares, evolutivas e/ou diretivas. O quadro construído por Sílvio Romero, Euclides da Cunha e Manoel Bomfim dialogava com os modelos teóricos formulados por Comte e Spencer, principalmente. Abundavam em seus escritos as dificuldades que os modelos evolucionistas iam acumulando justamente por construir modelos genéricos de explicação.

Pode-se dizer que os três pensadores brasileiros, mencionados no parágrafo anterior, ocuparam-se num primeiro momento, em mostrar o que impedia a construção de progressos civilizacionais capazes de mudar os indivíduos e as instituições. Somente debelando os fatores impeditivos é que o país poderia rumar-se evolutivamente para uma condição melhor socialmente. Há diferenças entre eles que vêm à tona com bastante força. Sílvio Romero parecia crer que alguns grupos (a elite intelectual, por exemplo) detinham maior capacidade de mudança que quaisquer outros setores, por isso essa elite, especificamente, deveria ter um papel primordial na construção da evolução. O fato de outros segmentos não possuírem tal capacidade aparecia, ora sanável ora insanável, em seus escritos. Todavia, seus escritos tinham dificuldades de lidar com a noção de evolução regressiva ${ }^{21}$, visto que ele estava imbuído fortemente das ideias de Spencer. Basta observar que, segundo ele, a mudança deveria ser pensada em razão da:

[...] Lei máxima de todos os fenômenos da história, como a de todos os fenômenos do mundo físico,

\footnotetext{
20 "O grau de maleabilidade e plasticidade (ou inversamente o grau de rigidez) varia de uma configuração para outra. Assim, também varia a cadeia de possibilidades de mudança. Uma configuração de pode ter um potencial de mudança muito maior do que outra. Uma vez mais, configurações diferentes podem ter um potencial para diferentes tipos de mudança. Por conseguinte, uma configuração pode ter um grande potencial de mudança sem que nenhuma das possíveis alterações seja de caráter evolutivo - nenhuma delas implica uma mudança estrutural; por mudanças entendemos potencial de poder de certas posições sociais (mais do que meras alterações de conjunto) entre os ocupantes dessas posições. Ou pode uma configuração ter pouco potencial e, no entanto, haver grandes possibilidades de ser evolutiva qualquer mudança que ocorra" (ELIAS, 1999; p.176).

${ }^{21}$ Charles Tilly em Clio e Minerva (1977) faz uma reflexão sobre as dificuldades das teorias clássicas e contemporâneas de trabalhar com a noção de evolução regressiva. Isto não significa, porém, que elas desconhecem a regressão, mas sim que se dá prioridade à evolução em detrimento dos recuos evolucionários. Esse é, então, um problema da teoria social em geral e não somente da teoria social brasileira.
} 


\title{
Ausência de projetos civilizacionais nos primeiros estudos sociais brasileiros
}

\begin{abstract}
a lei de evolução, cuja fórmula mais completa é aquela que é devida ao gênio de Herbert Spencer... Sabemos que não podem existir fatos sem antecedentes imediatos, sem a passagem de um estado homogêneo e incoerente a um estado de diferenciação e coerência, não podemos admitir o milagre da existência de instituições, quatro vezes seculares, no ar, sem a menor base na vida nacional (ROMERO, 1969; p. 264).
\end{abstract}

Manoel Bomfim, por outro lado, desdenhava da crença de Sílvio Romero na capacidade de mudança dos segmentos letrados. Para ele, a única possibilidade de ocorrer evoluções efetivas era a emergência de novas forças sociais (o proletariado político) capazes de guinar o país para algo completamente distinto de tudo o que havia vigorado até então. No entanto, Manoel Bomfim não cogitava também na noção de evolução regressiva. Ele insistia muito mais na noção de estagnação. Havia, segundo ele, na maioria das vezes, a sensação de que o país não saía do lugar no que diz respeito à possibilidade de vencer os autoritarismos arraigados na sociedade e no Estado. Ou seja, não havia avanços substantivos e capazes de transfigurar a vida social. Isso porque "o passado não nos dera, nem a educação social e política precisa para termos democracia de verdade, nem os meios de formação mental, donde pudesse resultar, desde logo, um pensamento próprio afirmativo" (BOMFIM, 1931; p. 8).

É possível perguntar o seguinte: Quando Euclides da Cunha afirmava taxativamente: ou nos civilizamos ou pereceremos, ele estava pressupondo a possibilidade de uma evolução regressiva? Há momentos em que é possível entender assim as suas reflexões, já que esta condição se inscrevia na condição de colonizador europeu que ele definia como um bárbaro colonizado ${ }^{22}$. Mas há, com muito mais frequência, argumentos fundados em uma linearidade histórica. Ou seja, havia dois caminhos: civilizar (como sinônimo de evoluir) ou perecer (sinônimo de estagnação e não de evolução regressiva).

Todos eles se batiam desesperadamente para encontrar, tanto na realidade quanto nas reflexões teóricas disponíveis, elementos capazes de desvendar a vida social brasileira no final do século 19 e no limiar do 20. Suas análises, mesmo com todos os limites, guardam a possibilidade de, na atualidade, ajudar a iluminar os desafios enfrentados pelo país naquele momento. Suas discussões sobre os avanços e não-avanços civilizacionais conseguiram construir alguns parâmetros que são hoje essenciais para o entendimento dos (des)caminhos seguidos pelo país.

\footnotetext{
22 "A ambição extraordinária de audazes aventureiros exigia a força inconsciente do selvagem para as longas pesquisas nos sertões... O missionário reagia à frente dos bárbaros arrancados às selvas, contra os bárbaros oriundos das terras civilizadas. Deste conflito resulta, em muitos pontos, a feição verdadeiramente heróica do nosso passado" (CUNHA, 1966h; p. 122).
} 


\section{HUM AN AS}

\section{Que projeto civilizacional poderia o país construir?}

Em termos gerais, os três pensadores brasileiros estudados neste artigo pressupunham uma irreversibilidade do processo civilizacional. Isso não significava, porém, que eles não tinham dúvidas, as que foram expressas muitas vezes, acerca da possibilidade de o país ingressar, de fato, numa rota econômica, política e social capaz de levar a mudanças expressivas tanto nos indivíduos (tornando-os, de fato, republicanos, democráticos e conscientes dos desafios que representavam a construção de um projeto de nação) quanto nas instituições. Eles buscavam compreender os motivos dificultadores da construção de práticas, de ações e de instituições políticas republicanas capazes de fomentar outro padrão de organização social que fosse compatível com os desafios postos no limiar do século 20. É nesse contexto que se pode compreender a assertiva de Euclides da Cunha em Os sertões (1995; p. 84): "Estamos condenados à civilização; ou progredimos ou desapareceremos". Para ele, não havia, de modo algum, qualquer outro caminho. Ou seja, o país não tinha qualquer alternativa senão esta de perseguir formas de construção de progressos econômicos, sociais e políticos.

Sílvio Romero, no texto $O$ Brasil social de Euclides da Cunha, levantava muitos questionamentos sobre esta assertiva presente em $O$ s sertões. Segundo ele, ora parecia que Cunha julgava a todos os brasileiros civilizados, ora parecia que uma parte dos habitantes do país era retardatária, ora o país, como um todo, era retardatário no que diz respeito a um projeto civilizacional. E os retardatários tendiam a ser extintos. Romero considerava que havia problemas a resolver nas proposições de Euclides da Cunha. Havia antinomias para explicar. Uma das indagações levantadas por aquele primeiro era: Quem, que segmentos sociais, que nações seriam extintos caso não fossem capazes de acompanhar um projeto civilizacional que muitas vezes era definido com base em histórias distintas da brasileira, por exemplo?

Note-se que Sílvio Romero, Euclides da Cunha e Manoel Bomfim tinham em mente um projeto civilizacional que era sim europeu, mas todos eles externavam um incômodo muito grande com a possibilidade de estar perseguindo algo copiado inteiramente da Europa. Quando Romero escreve sua reflexão crítica sobre Os sertões ele insistia, com muita ênfase, na necessidade de ajustar melhor as análises em razão das condições históricas vigentes no continente latino-americano:

Originaram-se [da] anomalia inicial várias antinomias que ainda hoje (primeiros anos do século XX) nos atropelam e fazem manquejar. A primeira dessas é a disparidade entre uma pequena elite de 


\section{Ausência de projetos civilizacionais nos primeiros estudos sociais brasileiros}

possuidores e proprietários e o avultadíssimo número dos que nada têm, nada possuem (ROMERO, 1979; p. 19).

É verificável que Sílvio Romero tentava fazer uma reflexão sobre as chances que cada grupo social possuía de sobreviver a um dado projeto civilizacional que deveria ainda ser construído. Como os trabalhadores do campo e da cidade seriam incorporados a tal projeto? E os fazendeiros com sua patronagem, com sua política de servidão? E diversos parasitas insaciáveis na sua sede por fortuna e riqueza, que lugar teriam em tal projeto? Isso demonstrava que Romero não pressupunha uma homogeneidade, entre os diversos segmentos sociais, no potencial de mudanças. Ele levantava tais questões para Euclides da Cunha porque julgava que este último era o homem certo para ajudá-lo a responder a tais desafios.

Seria possível, sem a existência de um ideal comum, construir algum projeto civilizacional que transfigurasse os indivíduos e as instituições? Por isso, a educação republicana deveria ser gestada por estas últimas, para que, a partir daí, fosse possível gerar um projeto coletivo de nação. Sem espírito de iniciativa, sem empreendimento, sem audácia não haveria nunca progresso e bem-estar, afirmava Romero. A base de um projeto civilizacional estava minada pela falta de uma consciência coletiva nacional, a qual ele atribuía à inexistência de um vasto operariado rural e/ou urbano, à inexistência de um trabalho regular e de uma pequena, uma média e uma grande burguesia dispostas ao empreendimento e à audácia. Tal base era implodida também pela farta politicagem mergulhada nas relações de favor e vantagens pessoais e/ ou de grupos.

Grosso modo, Romero alertava Euclides da Cunha quanto à possibilidade de que o Brasil estivesse condenado à não-civilidade social e política e não o contrário, conforme atestava o autor de Os sertões. Ou seja, que o país estava condenado à civilização ou ao perecimento. Talvez nem civilização nem perecimento. Talvez a nação fosse mantida indefinidamente entre a (im)possibilidade civilizacional. Tanto para Cunha quanto para Romero, se o país continuasse um joguete nas mãos das nações desenvolvidas, ele nunca construiria um projeto de nação apto a impulsionar tal condição civilizacional.

Não era possível considerar como projeto civilizacional um progresso arrastado pelas nações estrangeiras que sempre colocariam os países latinoamericanos em segundo plano. Por isso, Romero e Cunha advogavam que progresso e civilização eram sinônimos somente se houvesse a mobilização de braços, forças, esforços e ideias nacionais. Os processos civilizacionais deveriam ser planejados e calculados nos seus efeitos e nos seus resultados. 


\section{HUM ANAS}

A obsessão de Romero pelo controle de tais processos gerava um atrito significativo com Manoel Bomfim, o qual não media esforços para criticar a indisposição dos intelectuais brasileiros para enfrentar as imprevisibilidades que seriam geradas com os processos de mudança em andamento no início do século 20. Assim como Romero e Cunha, Bomfim também tecia uma crítica agressiva às intromissões estrangeiras no país. Todavia, ele via com muita desconfiança qualquer ideia de projeto civilizacional que não estivesse calcado principalmente na emergência de uma nova força social: o proletariado urbano politizado. Nessas condições, a industrialização era tida como causa e os progressos civilizacionais como efeito, os quais eram definidos como sepultadores do regresso social, da estagnação política e do conservantismo sistemático.

Bomfim considerava ainda que enquanto não fosse vencido o massacre do espírito público, não haveria qualquer chance de o país se civilizar. "O espírito público abaixava-se gradualmente sob a pressão do terror, enquanto o vício, cada vez mais requintado, se apossava placidamente do lugar vazio que deixava nas almas a dignidade, o sentimento e a energia da vontade pessoal, esmagado, destruído pelo medo" (BOMFIM, 1993; p. 115).

E por que era o conservantismo o maior inimigo de quaisquer projetos civilizacionais que derrotassem a mentalidade conservadora e autoritária? Por ser ele um conjunto de ações que visavam, no limiar do século 21, conservar o país nas condições de miserabilidade, pobreza, ausência de instrução técnica e profissionalizante, exclusão social e política. Por isso ele indagava:

É impossível que esses homens não reconheçam o
absurdo de apresentar como programa político “con-
servar". Conservar não pode constituir função es-
pecial, ativa, de ninguém; é uma função passiva. A
sociedade conserva-se, independente de qualquer
esforço; conserva-se... por uma função incons-
ciente, reflexa... Conservar é obra dos mortos. Vi-
ver é acrescentar alguma coisa ao que existe, elimi-
nar o que já não convém (BOMFIM, 1993; p. 162).

Manoel Bomfim problematizou a questão civilização contraposta à (in) (des)civilização e lançando mão da história política do país. Isso visava quebrar os argumentos que alegavam que as dificuldades civilizacionais estavam inscritas na cultura do povo brasileiro. Para ele, elas estavam sim assentadas em procedimentos dos dirigentes e dos dominantes. Esmiuçar tais formas de agir era a única maneira de compreender, de fato, onde estavam as razões da inexistência de um projeto nacional capaz de guinar o país rumo a um projeto de nação democrático e inclusivo. "Onde quer que surja a oposição conservadora, há um privilégio que se quer manter. Ela resiste pura e simplesmente ao progresso, 


\section{Ausência de projetos civilizacionais nos primeiros estudos sociais brasileiros}

que destruiria as vantagens dos grupos dominantes, afrontando preconceitos e superstições" (BOMFIM, 1993; p. 162).

Todavia, não se deve esquecer que, mesmo estando ele preocupado com as singularidades históricas do país, ele também abraçava a tese de que o progresso técnico e industrial seria a fonte da transfiguração dos procedimentos dos diversos grupos sociais. Os setores dirigentes seriam atingidos, em seu agir, pela industrialização, uma vez que esta faria emergir um proletariado que estaria em condições de forçar tais segmentos a mudar suas atitudes em relação ao país e aos demais segmentos sociais. Tal postura o aproximava mais do que ele próprio desejava de Spencer e de Comte. Este último:

Definiu o avanço da civilização como um processo evolutivo que diminuiu a premência das carências físicas e estimulou os poderes intelectuais dos seres humanos... Tal como Spencer, mais tarde, Comte propôs uma sociologia da modernidade que enfatizou a substituição da guerra como proeminente meta da sociedade por empreendimentos pacíficos centrados no comércio e na indústria (LEVINE, 1997; p. 274).

A relação de Manoel Bomfim com os pensadores que o influenciaram era conturbadíssima. Ele considerava que neste debate sobre povos civilizados e incivilizados, tanto Comte, quanto Spencer e Darwin teriam propiciado os instrumentos para uma desqualificação completa dos povos latino-americanos. Em seu modo de ver, todos esses pensadores europeus forneceram os instrumentais para o florescimento de uma "sociologia do egoísmo" na qual era defendido que os mais fortes (os europeus) sempre vencem em virtude de sua condição de superiormente civilizados. No processamento da vida social, dizia ele, não vencem os mais fortes, vencem sim os mais cruéis.

Bomfim insistia, portanto, que era necessário, para galgar uma condição mais justa, inclusiva e democrática, gerar, no país, um conhecimento próprio que pudesse dar conta das singularidades sociais brasileiras. Em $\mathrm{O}$ Brasil $\mathrm{Na}$ ção, ele faz um levantamento extenso sobre a emergência de formas de pensamento (romantismo, indianismo) que indicavam a possibilidade de emergir um pensamento nacional alimentado pelas singularidades culturais brasileiras. Emergia, assim, críticas aos dirigentes e a suas ações arrasadoras dos interesses nacionais. Nem tudo no país era incivilização e/ou descivilização, eram-no as ações dos dirigentes e dos dominantes que parasitavam a nação de modo a fazê-la murcha, destroçada, ressequida. Não havia projeto civilizacional possível com a permanência de um padrão de domínio sustentado por homens que não faziam outra coisa senão "transigir, dissimular, abjurar, desprezar princípios, sacrificar a pátria por motivos pessoais" (BOMFIM, 1931; p. 142). 


\title{
HUM AN AS
}

A nação brasileira seria, então, incivilizada enquanto a condescendência, o servilismo, a abjuração e a conciliação fossem orientadoras das práticas sociais e individuais. A transformação da conduta dos dirigentes e dominantes era condição absoluta para que fossem processadas mudanças no país. Todavia, Bomfim acreditava que tais câmbios deveriam ocorrer de modo planejado por alguns agentes sociais dispostos a levar a cabo uma transfiguração do país.

Note-se que Manoel Bomfim estava convicto de que os processos de mudanças sociais e políticas dependiam de ações planejadas, por alguns grupos e instituições. Daí sua ênfase na educação pública capaz de gerar condições para que os indivíduos não ficassem eternamente abandonados à própria sorte. Para ele, as ações deviam ser calculadas, planejadas e organizadas no sentido de resolver os problemas (pobreza, desemprego, fome, analfabetismo) da nação. Há alguns intérpretes de Norbert Elias que têm ressaltado a ingenuidade desta visão que insiste que o processo civilizador seria sempre um caminho racionalmente planejado por pessoas e/ou grupos. Veja-se a fala abaixo:

\begin{abstract}
Partiendo de la perspectiva de Elias, podemos decir que el proceso civilizador significa un cambio en la conducta y en las sensaciones en un punto específico, sin embargo, este cambio no se planea, pues nada en Historia indica que tal cambio se ha realizado racionalmente, por meio de cualquier acción educativa intencional de personas aisladas o de grupos (SIMÕES, 2008; p. 105).
\end{abstract}

A obra O processo civilizador (1994), de Elias favorece em alguns aspectos essa interpretação exposta acima, mas isso não aparece de modo idêntico em todas as suas reflexões. Ganha proeminência, em suas discussões, a ideia de que o processo civilizador vem de processos planejados e não-planejados ao mesmo tempo. No texto Tecnização e civilização (2006a), ele vai demonstrando como corriam simultaneamente os dois tipos de processos. São diversas as forças (planejadas e não-planejadas) que vão sendo eficazes. Através de processos de longa duração, há um extenso aprendizado que põe em movimento novas forças civilizacionais e descivilizacionais. Isso tudo não ocorre fora dos indivíduos, porquanto mobiliza muitos deles os quais dão muitos passos que levam a várias vitórias e a várias derrotas.

Pode-se dizer, então, que Manoel Bomfim se atinha, essencialmente, às ações planejadas, mesmo porque ele partilhava de uma visão diretiva acerca do processo histórico. Todavia, ele demonstrava, em O Brasil Nação (1931), 


\section{Ausência de projetos civilizacionais nos primeiros estudos sociais brasileiros}

que o processo descivilizador era algo institucionalizado no país. O que não significava que havia um plano concebido com esse objetivo. Havia, sim, uma luta para manter posições de poder que empurrava para longe qualquer possibilidade de desmantelar os padrões de organização social e de domínio em vigor.

À luz dos escritos de Elias, sobre as ações planejadas em favor do processo civilizacional, pode-se dizer que era cabível que Manoel Bomfim pensasse a construção de mudanças a partir de um longo processo de formação política e educacional dos brasileiros em geral. No caso do Brasil, era preciso vencer a resistência dos dirigentes que se recusavam a implantar uma educação formadora de sujeitos políticos ativos e conscientes. Havia uma luta inteira a ser feita visando combater os interesses personalistas e reafirmadores de um padrão de domínio autoritário que só interessava a alguns. Sem planos de ação não haveria qualquer mudança rumo a uma melhor distribuição do poder e da renda.

\section{Considerações finais}

Detecta-se que tanto Silvio Romero quanto Euclides da Cunha e Manoel Bomfim não supunham que a civilização era um estágio acabado, finalizado. Os três fazem críticas contundentes aos pensadores que consideravam que os europeus eram povos definitivamente civilizados. O autor de Os sertões deixa claro em várias ocasiões sua visão do europeu como o bárbaro civilizado. Em um artigo intitulado Garimpeiros (1966c), ele descrevia o europeu como aquele que apresentava todos os trejeitos civilizados com seus modos e modas (roupas) indicando uma condição que o distinguia dos demais bárbaros incivilizados que pelejavam nas minas de ouro, na condição de escravos. Em sua descrição ele afirmava que a aparência civilizada do colonizador gerava desconforto, uma vez que o chicote não lhe saía das mãos. Ele afirmava:

Parecia não haver intermediários àquela simbiose da escravidão com o ouro, porque não havia encontrá-los mesmo no agrupamento incaracterístico, e mais separador que unificador, dos solertes capitães-do-mato, dos meirinhos odientos, dos bravateadores oficiais de dragões, dos guarda-mares, dos escrivães, dos pedestres e dos exatores, açulados pelas ruas, farejando estradas e as picadas, perquerindo os córregos e os desmontes; em busca do escravo; filiando-se às pernas ágeis dos contrabandistas; colados no rastro dos contraventores; 
e espavorindo os faiscadores pobres, inquirindo, indagando, prendendo, intimando e, quase sempre, matando. O cacete de guarda-costas vibrava próximo do bastão de biqueira de ouro (CUNHA, 1966f; p. 124).

Em A América Latina: males de origem (1993), Manoel Bomfim deixou mais evidente - que os demais pensadores aqui analisados - sua descrença em um estágio civilizado capaz de dissuadir os povos do acometimento de inúmeras formas de violência. Ao questionar a tese de superioridade dos colonizadores, ele indagava: superior em quê, exatamente? E respondia: Em crueldade realmente não há povos superiores aos europeus.

De certa maneira, os intérpretes do Brasil selecionados para este trabalho tentavam desembaraçar o entrançado que observavam entre civilização e violência. É possível perceber em seus escritos a tentativa de ver, no futuro, a separação dessas duas condições (civilização e violência). Ou seja, a de um povo civilizado que buscaria debelar através da educação republicana (no caso de Romero), da democracia e da implementação de um Estado providência (no caso de Bomfim) as muitas formas de violência vigentes no país. No entanto, ora parecia que eles viam a civilização e a violência como uma antítese, ora parecia que não as viam necessariamente dessa forma. A violência poderia ser um meio para alcançar melhoramentos. Foi isso que E. da Cunha demonstrou em alguns textos, tais como $D a$ Independência à República (1966). Reiterando essa ideia, Manoel Bomfim, em O Brasil Nação, insistia na necessidade de "arriscar no espontâneo das energias sociais. Ter-se-á o caos, mas daí poderá brotar um novo tempo" (BOMFIM, 1931; p.340). A sua noção de progresso, de evolução estava atravessada pela ideia de que a mudança poderia fazer-se através de uma forma de violência. Ele dizia:

Toda evolução humana consiste, justamente, na ascensão dessa realidade instintiva para a plena moralidade e a justiça. Ora, nesse fim, a explosão revolucionária vale como depuração súbita, idêntica à mutação de formas, patente e necessária, na marcha social e na evolução biológica. Então, verifica-se, em toda luz - que o homem se torna fator decisivo do caso: a experiência acumulada na espécie é condensação de energias psíquicas, que a descarga revolução - transforma, imediatamente, em ação reformadora (BOMFIM, 1931b; p. 342). 


\section{Ausência de projetos civilizacionais nos primeiros estudos sociais brasileiros}

O debate sobre a possível oposição entre civilização e violência, já intuído pelos primeiros pensadores sociais brasileiros, pode ser constatado na discussão das Ciências Sociais, no decorrer do século 20. Norbert Elias foi o que mais se debruçou sobre isso:

Es conveniente recordar la idea planteada por Norbert Elias, demonstrando que civilización y violencia no son antítesis. El humano está en proceso continuo para civilizarse, es decir, para mejorar sus estándares de conducta y de comportamiento, controlar sus emociones, buscar las nuevas maneras de organizarse colectivamente, previniendo los conflictos basados en la violencia física tratando de dar prioridad a diálogo, a la construcción del argumento como instrumento principal de la defensa de sus intereses (SIMÕES, 2008; p. 97-8).

Enfim, pode-se dizer que Sílvio Romero, Euclides da Cunha e Manoel Bomfim estavam debatendo-se para encontrar formas de manejar ações que levassem o país a romper com um padrão de domínio e de organização social reforçador das exclusões e das desigualdades. Os processos civilizacionais adviriam de ações direcionadas nesse sentido. Norbert Elias $\left(1994 ; 2006^{\mathrm{a}}\right)$ demonstrou que um dos maiores equívocos dos teóricos clássicos (Comte, Spencer, Durkheim, entre outros), aos quais estes pensadores brasileiros se filiavam, foi supor que os processos civilizacionais decorrem somente de ações planejadas e intencionais. Os processos descivilizacionais podem derivar de efeitos colaterais de ações que visam gerar processos civilizadores. Supor um encadeamento linear ou diretivo é desconsiderar as ações não-planejadas e seus efeitos sobre o processo histórico.

\section{Referências bibliográficas}

AZEVEDO, F. de. Novos caminhos e novos fins. São Paulo: Melhoramentos, 1958.

AZEVEDO, F. de. Sociologia educacional. São Paulo: Melhoramentos, 1958a.

AZEVEDO, Fernando de. A educação e seus problemas. São Paulo: Melhoramentos, 1958b.

AZEVEDO, F. de. A cidade e o campo na civilização industrial e outros ensaios. São Paulo: Melhoramentos, 1962. 
BOMFIM, M. O Brasil Nação: realidade da soberania brasileira. Rio de Janeiro: Francisco Alves, 1931.

BOMFIM, M. O Brasil na história. Deturpações da tradição. Degradação política. Rio de Janeiro: Francisco Alves, 1931a.

BOMFIM, M. O Brasil na América: caracterização da formação brasileira. Rio de Janeiro: Topbooks, 1997.

BOMFIM, M. A América Latina: males de origem. Rio de Janeiro: Topbooks, 1993.

CANDIDO, A. Radicalismos. Estudos avançados, 4(8): 4-18, 1990.

CARVALHO, A.B. de \& BRANDÃO, C.F. Introdução à sociologia da cultura: Max Weber e Norbert Elias. São Paulo: Avercamp, 2005.

COLLINS, R. Theoretical sociology. San Diego: Hartcourt Brace Jovanivich, 1988.

CUNHA, E. da. Os sertões. Rio de Janeiro: Francisco Alves, 1995.

CUNHA, E. da. Da independência à República. In: Obra completa. Volume 1, p. 326-76. São Paulo: Aguilar, 1966.

CUNHA, E. da. Contrastes e confrontos. In: Obra completa. Volume 1, p. 151-55. São Paulo, Aguilar, $1966^{a}$.

CUNHA, E. da. À margem da história. In: Obra completa. Volume 1, p. $223-$ 384. São Paulo: Aguilar, 1966b.

CUNHA, E. da. Garimpeiros. In: Obra completa. Volume 1, p. 123-37. São Paulo: Aguilar, 1966c.

CUNHA, E. da. Plano de uma cruzada. In: Obra completa. Volume 1, p. 13041. São Paulo: Aguilar, 1966d.

CUNHA, E. da. Conflito inevitável. In: Obra completa. Volume 1, p. 155-59. São Paulo: Aguilar, 1966e.

CUNHA, E. da. Nativismo provisório. In: Obra completa. Volume 1, p. 18790. São Paulo: Aguilar, 1966f.

CUNHA, E. da. Temores vão. In: Obra completa. Volume 1, p. 173-76. São Paulo: Aguilar, 1966g. 


\section{Ausência de projetos civilizacionais nos primeiros estudos sociais brasileiros}

CUNHA, E. da. Anchieta. In: Obra completa. Volume 1, p. 121-23. São Paulo: Aguilar, 1966h.

CUNHA, E. da. Civilização. O Estado de São Paulo, São Paulo, 10 de Julho de 1904.

COMTE, A. Discurso sobre o espírito positivo. São Paulo e Porto Alegre: Globo e EdUSP, 1976.

DURKHEIM, E. A divisão do trabalho social. Lisboa: Editoria Presença, 1984.

ELIAS, N. O processo civilizador: Formação do Estado e civilização. Volume 2. Rio de Janeiro: Jorge Zahar, 1994.

ELIAS, N. Envolvimento e alienação. Rio de Janeiro: Bertrand Brasil, 1998.

ELIAS, N. Introdução à Sociologia. Lisboa: Edições 70, 1999.

ELIAS, N. As interdependências humanas - os processos das ligações sociais. In: Introdução à Sociologia. Lisboa: Edições 70, 2001.

ELIAS, N. Tarde demais ou cedo demais: notas sobre a classificação da teoria do processo e da figuração. In: Norbert Elias por ele mesmo. P. 144-63. Rio de Janeiro: Jorge Zahar, 2001.

ELIAS, N. Conceitos sociológicos fundamentais: civilização, figuração, processos sociais. In: F. NEIBURG \& L. WAISBORT (Orgs.). Escritos \& Ensaios. P. 21-33. Rio de Janeiro: Jorge Zahar, 2006.

ELIAS, N. Tecnização e civilização. In: F. NEIBURG \& L. WAISBORT (Orgs.). Escritos \& Ensaios. P. 35-67. Rio de Janeiro: Jorge Zahar, 2006 ${ }^{\mathrm{a}}$.

ELIAS, N. Processos de formação de Estados e construção de nações. In: F. NEIBURG \& L. WAISBORT (Orgs.). Escritos \& Ensaios. P. 153-65. Rio de Janeiro: Jorge Zahar, 2006b.

ELIAS, N. Para a fundamentação de uma teoria dos processos sociais. In: F. NEIBURG \& L. WAISBORT (Orgs.). Escritos \& Ensaios. P. 197-231. Rio de Janeiro: Jorge Zahar, 2006c.

FAORO, R. Os donos do poder: formação do patronato político brasileiro. Rio de Janeiro: Globo, 1989.

FAORO, R. A triste “modernização". Isto É/Senhor. São Paulo: n. 1113, p. 47, 23 jan 1991. 
FAORO, R. A modernização nacional. In: Existe um pensamento político brasileiro? P. 95-115. São Paulo: Ática, 1994.

FERNANDES, F. A sociologia no Brasil. Petrópolis: Vozes, 1977.

FURTADO, C. Dialética do desenvolvimento. Rio de Janeiro: Fundo de Cultura, 1964.

FURTADO, C. Criatividade e dependência na civilização industrial. Rio de Janeiro: Paz e Terra, 1978.

FURTADO, C. Brasil, a construção interrompida. São Paulo: Paz e Terra, 1992.

FURTADO, C. O capitalismo global. Rio de Janeiro: Paz e Terra, 1998.

GEBARA, A. Civilización y descivilización en América Latina: el caso brasileño. In: C. KAPLAN \& V. ORCE (Coords.). Poder, prácticas sociales y proceso civilizador: los usos de Norbert Elias. P. 25-32. Buenos Aires: Noveduc, 2009.

GEBARA, A. Portugueses, jesuítas y la educación de los indios bravos y bárbaros. In: C. KAPLAN (Org.). La civilización en cuestión: escritos inspirados en la obra de Norbert Elias. P. 51-80. Buenos Aires: Nino y Dávila, 2008.

GEBARA, A. Em torno da questão cultural e da educação: os processos civilizadores. In: A.B. de CARVALHO \& C.F. BRANDÃO (Orgs.). Introdução à sociologia da cultura: Max Weber e Norbert Elias. P. 105-18. São Paulo: Avercamp, 2005.

GODTHORPE, J.B. Herbert Spencer. In: T. Raison (Org.). Os precursores das Ciências Sociais. P. 83-91. Rio de Janeiro: Zahar, 1971.

GOODY, J. O roubo da história. São Paulo: Contexto, 2008.

GOODY, J. Entrevista. Disponível em: http://www.rosanapinheiromachado.com/ 2009/02/entrevista-com-goody-o-roubo-da.htm.

HOLANDA, S.B. de. O poder pessoal. In: História geral da civilização brasileira: o Brasil monárquico; do Império à República. p 72-8. São Paulo: Difel, 1972.

HOLANDA, S.B. de. A democracia improvisada. In: História geral da civilização brasileira: o Brasil monárquico; do Império à República. p. 79-87. São Paulo: Difel, 1972a . 
HOLANDA, S.B. de. A democracia é difícil. Veja, São Paulo, n.386, p.3-6, 28 jan. 1976. Entrevista.

HOLANDA, S.B. de. Raízes do Brasil. Rio de Janeiro: J. Olympio, 1987.

HUNTINGTON, S. O Choque de civilizações. Rio de Janeiro: Objetiva, 1997.

KAPLAN, C. (Org.) La civilización en cuestión: escritos inspirados en la obra de Norbert Elias. Buenos Aires: Nino y Dávila, 2008.

KAPLAN, C. \& ORCE, V. (Coords). Poder, prácticas sociales y proceso civilizador: los usos de Norbert Elias. Buenos Aires: Noveduc, 2009.

LEVINE, D. Visões da tradição sociológica. Rio de Janeiro: Jorge Zahar, 1997.

REZENDE MOTA, M.A. Sílvio Romero: Dilemas e combates no Brasil da virada do século XX. Rio de Janeiro: FGV, 2000.

REZENDE, M.J. de. Mudança social e conciliação em Euclides da Cunha. Acta Scientiarum, Maringá, 24(1): 189-99, 2002.

REZENDE, M.J. de. Sílvio Romero, Euclides da Cunha, Manoel Bomfim e o evolucionismo sociológico. Cadernos Ceru, 2(14): 257-80, 2003.

ROMERO, S. História da literatura brasileira. Volume 1. Rio de Janeiro: J. Olympio, 1943.

ROMERO, S. Obras filosóficas. Rio de Janeiro: J. Olympio, 1969.

ROMERO, S. Estudos sobre a poesia popular do Brasil. Petrópolis: Vozes, 1977.

ROMERO, S. Parlamentarismo e presidencialismo. Brasília: Senado Federal, 1979.

ROMERO, S. O Brasil social de Euclides da Cunha. In: Realidades e ilusões no Brasil: parlamentarismo e presidencialismo e outros ensaios. Petrópolis/ Aracaju: Vozes/Governo do Estado de Sergipe, 1979.

SIMÕES, J.L. Reflexiones sobre a desigualdad social, violencia y civilización en Brasil. In: C. KAPLAN (Org.). La civilización en cuestión: escritos inspirados en la obra de Norbert Elias. p. 95-115. Buenos Aires: Nino y Dávila, 2008.

SPENCER, H. Impérialisme et servitude. In: Faits et commentaires. p. 17792. Paris: Hachette, 1904. 
SPENCER, H. Retour a la barbarie. In: Faits et commentaires. p. 193-211. Paris: Hachette, 1904a.

SPENCER, H. Réglementations. In: Faits et commentaires. p. 211-24. Paris: Hachette, 1904b.

SPENCER, H. Faits et commentaires. Paris: Hachette, 1904c.

SPENCER, H. On social evolution. Chicago: University of Chicago Press, 1972. SPENCER, H. The study of sociology. Michigan: University of Michigan Press, 1961.

SOMBART, W. El burgues. Buenos Aires: Orisme Ediciones, 1953.

SOMBART, W. Lujo y capitalismo. Madrid: Alianza Editorial, 1979.

SZTOMPKA, P. A sociologia da mudança social. Rio de Janeiro: Civilização Brasileira, 1998.

TILLY, C. Clio e Minerva. In: P. BIRNBAUM \& F. CHAZEL. Teoria sociológica. p. 435-55. São Paulo: Hucitec e EdUSP, 1977.

WEBER, A. História de la cultura. México: Fondo de Cultura Económica, 1960.

WEBER, M. A ética protestante e o espírito do capitalismo. São Paulo: Pioneira, 1985.

WEBER, M. Economia e sociedade. Volume 1. Brasília: UNB, 1991. 